\title{
The Moderating Effect of Self-efficacy on the Relationship Between Internet Game Addiction and Aggression Among Korean Adolescents
}

\author{
Kang Sun Kyung ${ }^{1}$, Seungnam Shin ${ }^{2, *}$, Jung In Lee ${ }^{3}$ \\ ${ }^{1}$ Department of Social Welfare, Sogang University, Seoul, Korea \\ ${ }^{2}$ Law School, Ewha Womans University, Seoul, Korea \\ ${ }^{3}$ Department of Social Welfare, Sogang University, Seoul, Korea \\ Email address: \\ skshin2000@sogang.ac.kr (K. S. Kyung), hisam@ewha.ac.kr (S. Shin), takeandtime@naver.com (J. In Lee) \\ ${ }^{*}$ Corresponding author
}

\section{To cite this article:}

Kang Sun Kyung, Seungnam Shin, Jung In Lee. The Moderating Effect of Self-efficacy on the Relationship Between Internet Game Addiction and Aggression Among Korean Adolescents. Social Sciences. Vol. 10, No. 2, 2021, pp. 58-66. doi: 10.11648/j.ss.20211002.13

Received: March 13, 2021; Accepted: March 29, 2021; Published: April 7, 2021

\begin{abstract}
The purpose of this study is to exam the moderating effect of self-efficacy that can change and predict adolescent behavior in relation to how internet game addiction influences aggression. For this purpose, an online survey of a sample of 811 middle and high school teenagers who used smartphones was performed from August 8 to 16, 2019. The analysis of the resulting data revealed the following. First, the group at high risk of internet game addiction displayed greater aggressiveness than other groups. Second, it was empirically verified that self-efficacy is a variable controlling the relationship between adolescents' internet game addiction and aggression. Based on these results, implementing social welfare and educational intervention measures were discussed to reduce the problematic behaviors of addictive use and aggressiveness surrounding internet gaming. This study's limitation, as well as suggestions for further studies are as follows. Since no studies on clinical game addiction diagnosis were implemented, in-depth follow-up studies are required to verify the regulation effect of self-efficacy on internet game addiction and aggression in young people who have been diagnosed with game addiction. Further, variables related to parents and home life were not assessed. Thus, in relation to young people's game addiction and aggression, future studies of parent-child interaction and the regulation effect of family leisure activities are suggested.
\end{abstract}

Keywords: Internet Game Addiction, Aggression, Self-Efficacy, Cognitive Behavior Model, Moderating Effect

\section{Introduction}

In the $21^{\text {st }}$ century, alongside ubiquitously used digital devices, playing computer games has become part of young people's daily life. Today, internet gaming has evolved to create an indispensable social and cultural space. Although the Internet provides various uses and conveniences, such as for communicating, acquiring, or sharing information, game addiction, which can be generated through excessive use of the Internet for entertainment and gaming purposes, has emerged as a critical social problem, highlighting the Internet's dual nature. Particularly, internet game addiction among young people stretches beyond simply creating adverse side effects, snowballing into complete loss of control and obsessive use, thus highlighting the issue's gravity. Because addicted youths cannot distinguish between virtual reality and reality, aggressiveness may arise in the form of misdeeds and violent crimes, all committed while mimicking the content encountered during gameplay. In extreme cases, some cases even brought on shooting sprees $[1,2]$.

According to a 2017 survey on overindulgence in gaming [3], $85.7 \%$ and $67.7 \%$ of teenagers and those in their $20 \mathrm{~s}$ respectively responded that most of their internet use comprised of online gaming. Given that $99.9 \%$ of teenagers and people in their 20s use the Internet, it is safe to assume that numerous young people have been exposed to violent games. Kim [4] has argued that young people, who are still 
developing cognitively and emotionally, may suffer from a decreased ability to recognize reality and limited self-control capabilities because of the highly violent games they have encountered in the virtual confines of the Internet, leading to increased aggression. Again, because violent online games distort cognitive development along with the systems needed for thinking in the real world, deviant behaviors such as aggression are triggered.

Regarding game addiction, Davis' cognitive behavioral model [5] offers reasons for why cognitive distortions can trigger problematic, aggressive behaviors. In this model, the cause of game addiction in young people is formed through pathological use, such as heavy internet gaming. Individual characteristics, the environment, and a particular youth's media use experiences assume cognitive effects to create pathological use. This type of game addiction status ultimately leads to problematic social behaviors, including aggression. Maladaptive cognitions, the cognitive behavioral model's core, which cause pathological internet use, refer to negative thinking in assessing oneself and reality, along with self-doubt and low self-efficacy. One of the cognitive processes considered to be important by Bandura in predicting behavior and behavior changes is self-efficacy [6].

Bandura's model of self-efficacy and research supporting the role of self-efficacy in influencing outcome behaviors has been validated regarding a wide range of specific behaviors [7]. Self-efficacy is a variable that explains and predicts game addiction. Several prior studies have also addressed the feature of this variable. For instance, Kim [8] verified the effect of self-efficacy as a moderating variable in the relationship between the experience of violent PC games and aggressive behaviors. Kim confirmed a moderating effect of self-efficacy and self-efficacy's role of influencing individuals' intentional aggression. Roh and Kim [9] selected friend support as a social factor and self-efficacy as a moderating variable in order to examine how they interact with delinquent adolescents' addiction. Roh and Kim observed that addiction meaningfully decreased when the adolescents' self-efficacy increased, thus confirming the moderating effect of self-efficacy.

Therefore, this study utilizes the cognitive behavioral model to analyze the impact of internet game addiction on aggression in young people - as these have become serious social issues - and to verify the moderating effect of self-efficacy on these variables. Although numerous previous studies on internet game addiction and aggression among young people exist, few studies include a specific examination of the moderating effect of self-efficacy. Given this, it is expected that analyzing the moderating effect of self-efficacy by verifying the relationship between internet game addiction and aggression among youth will reveal numerous meaningful effects. In addition, based on the research findings, the purpose of this study is to provide basic data established by seeking measures to ease the aggression that emerges from internet game addiction among youth and improve their self-efficacy. To this end, the research questions were set as follows:

Research Question 1: What influence does internet game addiction have on aggression in young people?

Research Question 2: Does self-efficacy have a moderating effect between internet game addiction and aggression in young people?

\section{Theoretical Background and Literature Review}

\subsection{Cognitive Behavioral Model and Youth Internet Game Addiction}

Internet game addiction, a sub-category of internet addiction [10], causes considerable functional loss in the daily lives of those using the Internet excessively. Game addiction consists of obsessive dependence, long-term use forming tolerance, and withdrawal responses because it is a behavioral addiction caused by repeating a certain behavior over a long period [11]. As Eo [12] maintained, young people addicted to gaming lack self-control regarding their gaming habits and lose control over their will to judge when and how they play. Even when suffering from the negative effects of gaming, they continue to play and, because of the resulting ambiguity between reality and virtual reality, may struggle as they try to adapt in terms of social functioning. In addition to this loss of control, game addiction causes maladaptation to daily and school life, degradation of cognition and emotional control, anxiety and isolation in interpersonal relations, and adverse physical effects (decreased vision, lack of sleep, etc.), along with deviant behaviors, all presenting the common characteristics of addiction that cause people to experience difficulties in daily life [13].

Various perspectives include explanations for why young people become easily addicted to gaming. Kim [14] has found that, during adolescence, people experience anxiety and internal conflicts relating to adaptation arising from issues such as a rapidly changing society, the burden of studies, and the tasks of maturing and developing. Young people, in particular, are in a "defenseless state" against addiction: they exhibit higher risks for indulging in addiction. Kim and $\mathrm{Yu}$ [13] identified the unique characteristics of online gaming and the problem of there being limited options for leisure and cultural spaces catering to the youth as the principal culprits behind addiction. Online games allow young people who face considerable stress from their studies to easily access and enjoy leisure activities without any remarkable restrictions in time, space, and expense. Young [11] has also considered the reasons for indulging in internet gaming and has recognized the characteristics of easy access, excitement, and anonymity. These factors provide young people wishing to escape from reality with favorable conditions for entering a virtual space. In addition, while playing video games, they can freely express their frustrations in manners that they would never reveal in the real world.

Davis [5] has approached internet game addiction among young people and its related causes through his cognitive behavioral model using the concept of pathological internet 
use (PIU). Davis construed a model of PIU based upon the assumption that PIU is the result of faulty cognitions paired with behaviors that serve to strengthen the dysfunctional response. In this model, the personality based on distal contributory causes (psychopathological factors that are vulnerable to addiction, e.g. depression, anxiety, stress, and substance dependence), maladaptive cognitions based on proximal contributory causes (e.g. self-doubt, low self-efficacy, and negative self-evaluation), and the experience of using the Internet trigger cognitive distortions. Maladaptive cognitions refer to all negative ideas, including self-doubt, low self-efficacy, and cognitive distortion in negative self-assessment. The most prominent symptoms of the maladaptive cognitions are obsessive thoughts about the Internet, reduced impulse control, lack of ability to stop using the Internet, and a belief that the Internet is the individual's only social support. This pathological status, ultimately, causes problematic social behaviors, such as aggression.

\subsection{Aggression}

Aggression, as a personal characteristic, refers to behaviors conducted with the intention of harming others [15]. According to Bandura [16], aggression relates not only to harming others and overt, socially sanctioned behaviors but also includes intention and motive. People learn aggressive behaviors during socialization in childhood, meaning that, if agents are socialized toward impulsiveness, have poor ethical judgment, and positively assess aggression at a young age, their potential for becoming aggressive adults is high. Anderson and Bushman [17] have also referred to aggression as a "behavior and tendency to harm others," categorizing the internal aspects of aggression that transcend overt actions. These constitute 'verbal aggression,' which damages others through written and verbal expression, 'relational or indirect aggression,' which causes others difficulty by gossiping and spreading lies, 'physical aggression,' which damages the body, and 'violence,' which signifies a physical attack and the tendency to damage others in extreme forms.

In previous studies on youth aggression, all male and female students displayed aggression; however, male subjects enacted a greater number of overt physically and verbally aggressive acts [18]. Seo [19] has maintained that aggression during adolescence represents an extremely severe and complex phenomenon. In other words, aggression expressed in the developmental stages of adolescence is instinctual. However, if aggression is inadequately addressed, the attack impulse increases and problem behaviors ensue, leading, in extreme cases, to violent crimes. The variables related to internet game addiction among young people and to aggression are based on the gender gap [18], game-playing hours [20], self-esteem [21], self-control [22], self-efficacy [20], violence [23], parenting attitudes [15], parent-child interactions [24], school life [25], etc.

Based on the mentioned studies, it is possible to make assumptions about the influence of internet game addiction on aggression among young people; however, determining that this influence is absolute is impossible. As Davis [5] has suggested, within the cognitive behavioral model, the decisive factors that trigger aggressive actions in young people do not only include emotional and environmental factors. Unrealistic thinking and illogical deduction interference, which affect normal information processing and distort situations to bring about undesired problematic behaviors, also deserve consideration.

\subsection{Self-efficacy}

Self-efficacy theory hinges on viewing self-efficacy as the most powerful motivator to act. As mentioned, in the cognitive behavioral model, self-efficacy plays the central role as a powerful influencer over negative cognition from internet game addiction [5]. Self-efficacy indicates confidence in one's ability to produce specific performances in a given situation [16].

According to Bandura [16], the four factors of mastery experience-vicarious experience, verbal persuasion, and physiological and/or affective states - can improve self-efficacy. The mastery experience increases self-efficacy when one successfully finishes a specific task, leading to self-confidence and the conviction that a task can be implemented again successfully under similar circumstances. Vicarious experience refers to the indirect influence that others' successes have over self-efficacy, although it is relatively weak compared to self-achievement. Verbal persuasion means that one supports others verbally, instilling the belief that they can successfully implement something. Lastly, the factor of physiological and/or affective states refers to the greater success that one can attain while implementing tasks in mentally stable conditions in contrast to mental conditions of anxiety or nervousness. Specifically, doubt about one's ability and anxiety while implementing a task imply low self-efficacy. In this case, one can easily quit or avoid the task. However, someone with high self-efficacy will assume the challenge of a task and endeavor to succeed. Therefore, self-efficacy is a critical psychological variable warranting consideration when adolescents experience numerous challenges and changes.

Jung [26] has argued that self-efficacy increases during adolescence and motivates individuals to progress energetically throughout their lifetime. Additionally, people with low self-efficacy have low self-confidence and easily avoid challenges or quit when encountering difficulties, also displaying a higher propensity for depression because they do not have confidence in their own capabilities. Based on this background, self-efficacy is considered an influential variable that can explain aggression and various types of addiction [4] [22]. In addition, when people face interpersonal difficulties in real life, they tend to develop addictions or indulge in internet games. Self-efficacy is a meaningful variable that buffers the negative effects of internet game addiction.

A moderating effect means that the third variable's characteristics involved in the relationship between the independent variable and the dependent variable influence the two variables in different directions and magnitudes 
[27]. This study utilizes self-efficacy as a moderating variable, linking the independent and the dependent variables. More specifically, this study sets game addiction and aggression as the independent and the dependent variables, respectively. In previous studies, self-efficacy has been regarded as one of the most persuasive mechanism that induces human behavior $[16,20,26]$. In line with these studies, this study tries to examine whether self-efficacy is a psychological factor that can induce positive behavioral development for adolescents by properly intervening in adolescents' aggressive behaviors.

\subsection{Internet Game Addiction Among Adolescents, Aggression, and Self-efficacy}

Internet game addiction, as an addiction type, is the largest source of individual and social problems regarding young people. The reason for this is that internet game addiction among adolescents commonly generates academic and interpersonal problems and causes negative results, including physical and mental impacts [28]. Young people who are addicted to internet games are impulsive, demonstrate poor abilities to solve social problems, and tend to identify with their game-world characters. Simultaneously, as they become addicted to gaming, they tend to confuse people in reality with villainous game characters, thus becoming further isolated from reality [29].

With youths addicted to internet gaming, they exhibit higher aggression levels [23] as the level of game addiction increases [2], and as exposure to games lengthens [20], aggression tends to increase. In other study, adolescents excessively exposed to violent games tend to have a weaker self-regulation, and become more insensitive to aggression and violence. Consequently, their addiction to games can lead to aggressive behaviors [4]. Further, a study with a cross-sectional design showed that externalizing behavior problems such as aggression is significantly associated with the amount of internet gaming [30]. Thus, aggression is generally considered to be a consequence of internet game playing [31]. However, some research findings demonstrated that internet gaming and aggression do not significantly correlate [32]. Other research also demonstrates that young people who already have aggressive tendencies tend to indulge in internet gaming, leading to internet game addiction [33]. It is also possible that internet game addiction and the problem of aggression have the same shared risk factors.

Kim and Jeon [34] have argued that young people with high self-efficacy levels could control aggressive behaviors, thus enabling them to adapt successfully to school life, highlighting the importance of self-efficacy. Kim's [14] research findings demonstrate that young people with high self-efficacy can control outside influences and suppress internet game addiction. Therefore, as Kim [14] has mentioned, education to improve self-efficacy among young people helps prevent internet game addiction. These research findings reveal that self-efficacy has a significant negative relationship with game addiction. This also means that high self-efficacy in real life can decrease game-playing hours and lower the level of addiction.

However, other research findings have revealed the opposite. Cho [35] argued that the aggressive actions conducted in internet games provide people with a vicarious experience that causes their aggressive actions in daily life to decrease. The inconsistencies in research findings on the relationship between self-efficacy and aggression can be interpreted as requiring further in-depth studies in this field. Based on these findings, in this study, the moderating effect of self-efficacy was explored in relation to internet game addiction and aggression.

\section{Research Methods}

\subsection{Participants and Data Collection}

The participants in this research included Korean middle and high school students who own smartphones. Using quota random sampling, the researchers applied quotas on the age group of 14-18. From this information, the impact of internet game addiction on aggression among the subjects nationwide has been explored. An internet survey was conducted by e-mail, from August 8 to 16, 2019. Inappropriate responses, such as responses based on patterns, were deleted from the data, leaving 811 responses for use in the final analysis.

\subsection{Measures}

\subsubsection{Aggression}

Inquiries on aggression, the dependent variable of the study, were six in number. They comprised the measures that the National Youth Policy Institute's Korean Children and Youth Panel Survey (KCYPS) used. Each question was measured using a 4-point Likert scale, with high scores indicating high aggression levels. To measure the level of aggression, six negative questions were inversely coded. The average value was calculated and used for analysis. Cronbach's $\alpha$, a reliability coefficient, was. 907.

\subsubsection{Internet Game Addiction}

Game addiction, an independent variable in this study, was measured by using Kim et al.'s Korean Game Addiction Scale for Children and Adolescents [33]. Consisting of a total of seven sub-factors, such as 'tolerance,' 'withdrawal,' 'excessive time consumption,' 'control damage,' and 'compulsive use,' this scale consists of a total of 21 questions (three questions for each of the seven sub-factors). The response to each question is measured on a 4-point Likert scale. The higher the score, the stronger the addiction to games. Game addiction scores range from 0 to 63 points on a total of 21 questions, and the range of scores for each sub-factor ranges from 0 to 9 points. This scale diagnoses game addiction by evaluating the 'total symptom score' of the sub-factor and the 'symptom presence' of the category form together. Therefore, individual questions that measure game addiction are quantified and measured according to the perspective of sub-factors. In other words, this study applies 
a categorical approach that evaluates the presence of a symptom when the total score of the response indicating the symptom ( 2 points out of $0 \sim 3$ points) reaches 6 points or more in the sub-factor. If three or more of the seven subfactors score at least 6 , the evaluation indicates addiction. If there are more than 6 points in one to two sub-factors, it is considered a boundary. If there are zero sub-factors with 6 points or more, it is classified as normal. In this study, Cronbach's $\alpha$ coefficient was. 970 .

\subsubsection{Self-efficacy}

In this study, Tipton and Worthington's general measure of self-efficacy [36], which Yang [37] adapted, was used. It comprises 18 questions, covering confidence, self-control efficacy, and the difficulty level of a task to measure self-efficacy in general circumstances. The questions were applied using a 7-point Likert scale. In this study, the Cronbach a coefficient was.922, confirming that the reliability was high and that no particular issues existed regarding reliability.

\subsubsection{Control Variables}

Control variables were measured by classifying gender, grades, average monthly household income, whether the respondents were from double-income families, average weekly hours of smartphone use, and leisure activities (games, etc.) and communication (e-mail), and their average use rate of these per day. To conduct the analysis, the values were converted into dummy variables. For example, the gender values were male student $=1$, female student $=0$, and middle school (grades 7-9) $=0$, whereas high school $($ grades $10-12)=1$. Average monthly household income was classified as less than KRW 2 million, KRW 2-4 million, KRW 4-6 million, and over KRW 6 million. The values for being from double-income families were yes $=1$ and no $=0$. Average weekly smartphone use (in hours) was applied using the standard of 4.4 hours, where less than 4.4 hours $=0$ and more than 4.4 hours $=1$. The daily average use rate for leisure activities (games, etc.) was applied using the standard of $33 \%$, where lower than $33 \%=0$ and higher than $33 \%=1$.

\section{Findings}

\subsection{Socio-Demographic Characteristics}

The analysis results of the participants' characteristics are shown in Table 1. The number of participants was 811 , with 391 males (48.2\%) and 420 females (51.8\%), meaning a greater number of females constituted the sample. The grade items produced 322 middle school students (39.7\%) and 489 high school students (60.3\%), with relatively more high school students. The most common average monthly household income was KRW 24 million $(294,36.3 \%)$, followed by KRW 4-6 million (227, 28.0\%), and KRW 6 million and more (191, 23.6\%). A total of 525 respondents $(64.7 \%)$ answered 'yes' to the question on double income, whereas 286 respondents
(35.3\%) replied 'no,' showing that over half of the respondents were from double-income families. To the question on weekly average smartphone use, most respondents replied $2-4.4$ hours $(361,44.5 \%)$, followed by the group reporting over 4.4 hours of use $(320,39.5 \%)$. Those who used smartphones for less than an hour formed the smallest group, with $130(16.0 \%)$. To the question on the purpose of using digital devices, 232 (28.6\%) respondents replied that their average daily use rate for games was higher than $45 \%$ and that they used digital devices for leisure activities (gaming), whereas for those whose average daily use rate was $25 \sim 50 \%, 429$ (52.9\%) responded that they communicated with others through digital devices. Those who answered that they used their devices for educational or business searches formed a substantial group, with $333(41.1 \%)$ and 365 (45.0\%), respectively; however, the response rates for 'non-educational use' and 'non-business use' were higher.

Table 1. General Characteristics of Participants of Study.

\begin{tabular}{|c|c|c|c|}
\hline Classification & & $\begin{array}{l}\text { Frequency } \\
\text { (numbers) }\end{array}$ & Rate (\%) \\
\hline \multirow{2}{*}{ Gender } & M & 391 & 48.2 \\
\hline & $\mathrm{F}$ & 420 & 51.8 \\
\hline \multirow{2}{*}{ Grade } & Junior High Students & 322 & 39.7 \\
\hline & High School Students & 489 & 60.3 \\
\hline \multirow{4}{*}{$\begin{array}{l}\text { Monthly average } \\
\text { household income } \\
\text { (unit: } 10 \text { thousand } \\
\text { KRW) }\end{array}$} & Less than 200 & 99 & 12.2 \\
\hline & $200-400$ & 294 & 36.3 \\
\hline & $400-600$ & 227 & 28.0 \\
\hline & 600 and above & 191 & 23.6 \\
\hline \multirow{2}{*}{ Dual income } & Yes & 525 & 64.7 \\
\hline & No & 286 & 35.3 \\
\hline \multirow{4}{*}{$\begin{array}{l}\text { Weekly average } \\
\text { hours of } \\
\text { smart-phone use }\end{array}$} & Less than an hour & 130 & 16.0 \\
\hline & $1 \sim 2$ hour & 142 & 17.5 \\
\hline & $2 \sim 3$ hour & 135 & 16.6 \\
\hline & 3 and longer & 404 & 49.8 \\
\hline \multirow{3}{*}{$\begin{array}{l}\text { Daily average } \\
\text { leisure rate } \\
\text { (games, etc.) }\end{array}$} & Less than $25 \%$ & 315 & 38.8 \\
\hline & $25 \sim 45 \%$ & 288 & 35.5 \\
\hline & $45 \%$ and above & 232 & 28.6 \\
\hline \multirow{3}{*}{$\begin{array}{l}\text { Communication } \\
\text { (Kakao Talk, } \\
\text { e-mail) }\end{array}$} & Less than $25 \%$ & 181 & 22.3 \\
\hline & $25 \sim 50 \%$ & 429 & 52.9 \\
\hline & $50 \%$ and above & 201 & 24.8 \\
\hline \multirow{2}{*}{ Education/learning } & Used & 333 & 41.1 \\
\hline & Not used & 478 & 58.9 \\
\hline \multirow{3}{*}{$\begin{array}{l}\text { Search for } \\
\text { studies/work } \\
\text { Total }\end{array}$} & Used & 365 & 45.0 \\
\hline & Not used & 446 & 55.0 \\
\hline & & 811 & 100 \\
\hline
\end{tabular}

\subsection{Comparative Analysis by Internet Game Addict Groups}

To check for aggression level differences among young people with internet game addictions, a one-way ANOVA was conducted (Table 2), which revealed that the groups' differences in internet game addiction levels were statistically significant. Based on post-hoc verification (Dunett T3), the young people's group at high risk of internet game addiction demonstrated higher aggression levels. The differences in self-efficacy, according to the level of internet game addiction, were not statistically significant. 
Table 2. Results of Comparative Analysis by Level of Internet Game Addiction.

\begin{tabular}{|c|c|c|c|c|c|c|}
\hline $\begin{array}{l}\text { Dependent } \\
\text { variable }\end{array}$ & $\begin{array}{l}\text { Internet Game addict group } \\
(\mathrm{n}=\mathbf{8 1 1})\end{array}$ & $\mathbf{N}$ & Average & $\begin{array}{l}\text { Standard } \\
\text { deviation }\end{array}$ & $\begin{array}{l}\text { F Value/significance } \\
\text { probability }\end{array}$ & $\begin{array}{l}\text { Post hoc comparison } \\
\text { (Dunnett T3) }\end{array}$ \\
\hline \multirow{3}{*}{ Aggression } & normal (a) & 260 & 2.10 & .952 & \multirow{3}{*}{$7.27 / .001 * * *$} & \multirow{6}{*}{$\mathrm{a}, \mathrm{b}<\mathrm{c}$} \\
\hline & risk (b) & 283 & 2.27 & .807 & & \\
\hline & high risk (c) & 268 & 2.36 & .616 & & \\
\hline \multirow{3}{*}{$\begin{array}{l}\text { Self- } \\
\text { efficacy }\end{array}$} & normal (a) & 260 & 4.34 & 1.11 & \multirow{3}{*}{$.834 / .435$} & \\
\hline & risk (b) & 283 & 4.41 & 1.00 & & \\
\hline & high risk (c) & 268 & 4.30 & 1.02 & & \\
\hline
\end{tabular}

$* \mathrm{p}<.05, * * \mathrm{p}<.01, * * * \mathrm{p}<.001$

$※$ Analysis of control variables was not shown in the Table 2 because they were not statistically significant in relation to the dependent variable of aggression.

\subsection{Correlation Among the Major Variables}

Table 3 shows the results of the correlation analysis of the major variables in this study. The analysis revealed that internet game addiction and aggression $(\mathrm{r}=.132, \mathrm{p}<.01)$ are significantly positively correlated and aggression and self-efficacy $(r=-.210$ $\mathrm{p}<.01)$ are significantly negatively correlated.

Table 3. Results of Correlation Analysis on Major Variables.

\begin{tabular}{lllll}
\hline Variable & Average & Standard deviation & $\mathbf{1}$ & $\mathbf{2}$ \\
\hline 1. Internet addiction & 1.01 & .807 & 1 & \\
2. Aggression & 2.245 & .8083 & $.132 * *$ & 1 \\
3. Self-efficacy & 4.356 & 1.044 & -.016 & $-.210 * *$ \\
\hline$* \mathrm{p}<.05, * * \mathrm{p}<.01, * * * \mathrm{p}<.001$ & & &
\end{tabular}

\subsection{Moderating Effect of Self-efficacy on Aggression Related to Internet Game Addiction}

Regarding aggression related to internet game addiction among young people, a hierarchical moderated regression analysis was conducted to verify the moderating effect of self-efficacy (Table 4). First, regarding the explanation of Model 1, where only independent variables were input at $2.0 \%$ $(\mathrm{F}=14.247, \mathrm{p}<.001)$, the $\beta$ value for aggression was. 132 ( $\mathrm{p}$ $<.001$ ), meaning that it is statistically significant.

Second, self-efficacy as an independent and moderating variable was additionally input in Model 2; its explanation was $5.8 \%(\mathrm{~F}=37.178, \mathrm{p}<.001)$, meaning that it is significantly higher than that of Model 1 . This reveals that, as internet game addiction $(\beta=.128, \mathrm{p}<.001)$ increases, aggression also increases, whereas lowered self-efficacy $(\beta=$ $-.208, \mathrm{p}<.001$ ) means that aggression will be higher.

Third, to verify the moderating effect of self-efficacy, the interactive term of internet game addiction $\times$ self-efficacy variable was input in Model 3. The explanation of the model was $6.6 \%(\mathrm{~F}=7.782, \mathrm{p}<.01)$, a significant increase from Model 2. In addition, the regulating effect of internet game addiction $\times$ self-efficacy $(\beta=.095, \mathrm{p}<.01)$ was confirmed as having a statistically significant effect. Therefore, the effect of internet game addiction on aggression demonstrated that young people's self-efficacy could act as a critical moderating factor. In addition, internet game addiction and aggression $(\beta$ $=.130 \mathrm{p}<.001)$ and self-efficacy $(\beta=-.200, \mathrm{p}<.001)$ were negatively correlated, meaning that they are highly statistically influential.

Additionally, both groups with high and low self-efficacy inclined towards a negative direction. This means that the level of self-efficacy controls aggression. In addition, the high self-efficacy group, compared to the low self-efficacy group, presented lower levels in terms of the extent of decreased aggression among internet game addicts.

Table 4. Moderation Regression Analysis on Self-efficacy in the Relationship between Internet Game Addiction and Aggression.

\begin{tabular}{|c|c|c|c|c|c|c|c|c|c|c|}
\hline \multirow{2}{*}{ Variable } & & & \multicolumn{3}{|c|}{ Unstandardized Coefficients } & \multirow{2}{*}{$\begin{array}{l}\text { Standardized } \\
\text { Coefficients }(\beta) \\
\end{array}$} & \multirow{2}{*}{$\mathbf{t}$} & \multirow{2}{*}{ Sig. } & \multicolumn{2}{|c|}{ Collinearity statistics } \\
\hline & & & B & S. E. & & & & & Tolerance & VIF \\
\hline Model 1 & \multicolumn{2}{|c|}{ Constant } & 2.11 & .045 & & - & 46.824 & .000 & - & - \\
\hline \multirow{3}{*}{ Model 2} & \multicolumn{2}{|c|}{ Constant } & 2.814 & .128 & & - & 22.771 & .000 & - & - \\
\hline & \multicolumn{2}{|c|}{ Internet game addiction } & .135 & .034 & & .128 & 3.762 & $.000 * * *$ & .947 & 1.056 \\
\hline & \multicolumn{2}{|c|}{ Self-efficacy } & -.157 & .026 & & -.208 & -6.097 & $.000 * * *$ & .978 & 1.023 \\
\hline \multirow{3}{*}{ Model 3} & \multicolumn{2}{|c|}{ Internet game addiction (L) } & .131 & .034 & & .130 & 3.837 & $.000 * * *$ & .466 & 1.001 \\
\hline & \multicolumn{2}{|c|}{ Self-efficacy (M) } & -.155 & .026 & & -.200 & -5.866 & $.000 * *$ & .873 & 1.007 \\
\hline & \multicolumn{2}{|c|}{$(\mathrm{L} \mathrm{X} \mathrm{M})$} & .153 & .055 & & .095 & 2.790 & $.005^{* * *}$ & .435 & 1.008 \\
\hline \multirow{2}{*}{ Model } & \multirow{2}{*}{$\mathbf{R}$} & \multirow{2}{*}{ R Square } & \multirow{2}{*}{\multicolumn{2}{|c|}{ Adjusted R square }} & \multirow{2}{*}{ S. E. } & \multirow{2}{*}{ R Change } & \multicolumn{2}{|l|}{ Change Statistics } & & \\
\hline & & & & & & & F Square Change & df1 & df2 & Sig \\
\hline 1 & .172 & .030 & .020 & & .800 & .017 & 14.247 & 1 & 809 & $.000 * * *$ \\
\hline 2 & .264 & .061 & .058 & & .784 & .043 & 34.178 & 1 & 808 & $.000 * * *$ \\
\hline 3 & .264 & .078 & .067 & & .781 & .009 & 7.782 & 2 & 807 & $.005^{* *}$ \\
\hline
\end{tabular}

$* \mathrm{p}<.05, * * \mathrm{p}<.01, * * * \mathrm{p}<.001$ 


\section{Discussion and Conclusion}

\subsection{Discussion}

Analysis of the research findings are discussed as follows.

First, regarding the characteristics of the participants for this study, 322 were middle school students (39.7\%) and 489 were high school students $(60.3 \%)$. Among them, those who spent over 3 hours per week using digital devices (on average) comprised the largest portion, with $49.8 \%$, or 404 respondents. In contrast, the smallest portion $(16.0 \%$, or 130 respondents) averaged less than 1 hour of digital device use per week. Regarding the purpose of using digital devices, 232 respondents $(28.6 \%)$ proffered that their average daily rate of gaming exceeded $45 \%$, stating that they played games for leisure, whereas 429 respondents $(52.9 \%)$ reported that they used their devices for communication. Consequently, the analysis of the above results revealed that the higher risk group of internet game addiction displayed the higher aggression level compared to other groups. Thus, early treatment of internet game addiction for adolescents cannot be neglected.

Second, the correlation analysis between the levels of internet game addiction among young people, aggression, and self-efficacy revealed that internet game addiction was significantly positively correlated to aggression and that aggression was significantly negatively correlated to self-efficacy. This result shares the same context with advanced research [21] that supported the existence of a positive correlation between young people's levels of internet game addiction and aggression. Simultaneously, a moderating effect could be projected because no significant correlation existed between the level of internet game addiction and self-efficacy.

Third, to verify the moderating effect of self-efficacy in the relationship between young people's internet game addiction and aggression, hierarchical moderation regression was conducted. In Model 1, internet game addiction had a positive effect on aggression. In Model 2, self-efficacy had a negative effect on aggression. These results share the same context as that of advanced research, demonstrating that, as the level of internet game addiction increases, aggression also increases [23], as well as that of advanced research providing evidence that young people with lower self-efficacy levels displayed increased aggression [25].

Lastly, Model 3, which results from verifying the regulation effect, demonstrated that, as internet game addiction levels among young people increase, aggression also increases. Therefore, empirical confirmation that self-efficacy can control the relationship between internet game addiction among young people and aggression was possible. In other words, young people's internet game addiction affects aggression; however, self-efficacy simultaneously buffers this effect and potentially decreases aggression. This mirrors the results of Park and Kim's study [38]. However, finding any advanced studies on self-efficacy's regulation effect relating to internet game addiction and aggression is difficult, and the desire remains to conduct various studies related to this matter.

This study's results include methods that social work practitioners and other healthcare professionals could adopt to develop programs or services. First, young people's internet game addiction increases aggression and, in turn, aggressive behaviors negatively affect family life, inter-personal relations, and school life for young people, causing numerous problems across various aspects of life. In particular, cases of violence and even murders carried out while imitating internet game content demonstrate the gravity of game addiction among young people. Against this backdrop, to prevent aggression in young people, first, prevention education and counseling for young internet game addicts should be conducted. To this end, young people must recognize the risks and gravity of game addiction. Concurrently, through early screening tests for internet game addiction, the number of potential victims could be minimized, and institutionalized counseling and treatment programs for young addicts or those at high risk of addiction should be implemented. Internet game addiction, like psychoactive substance abuse or pathological gambling, is associated with extremely high impulsiveness. With prolonged excessive game playing, issues of self-control emerge and living a normal life becomes impossible. This is why treatment and intervention is required [28]. Additionally, the local community or youth welfare centers should conduct compulsory education on internet game addiction prevention and promote appropriate internet use through cultural experience educational programs. Contemporarily, attempting to teach young people to form beneficial habits by limiting the hours and amount of gameplay is also desirable, thus mitigating the risk that aggression from game addiction will lead to problematic behaviors.

Second, in accordance with Davis' cognitive behavioral model [5], young people's game addiction issues emerge from negative cognitions because of their vulnerabilities and environment, along with their exposure to the Internet. Low self-efficacy derived from negative cognitions of themselves increases aggression related to internet game addiction. Therefore, developing programs that decrease the negative effects of aggression and improve self-efficacy becomes critical. Under such circumstances, actively supporting the development and facilitation of programs designed to improve self-efficacy is necessary. Improved self-efficacy is likely to enhance confidence, feelings of achievement, and self-control and decrease young people's aggression levels, as well as game addiction.

Third, teenagers who spend most of their time at school can benefit from having professional counselors with expertise in internet addiction dispatched to their schools because this will be extremely helpful in preventing internet game addiction from an educational perspective. To this end, school counselors specialized in internet addiction must be fostered and dispatched; this can be achieved by establishing educational programs, institutional tools, and financial 
support designed to enhance addiction-counseling capabilities. Involved organizations (including schools) with concerns for internet game addiction issues, along with social welfare institutions, youth organizations, medical institutions, and local governments, need to form a cooperative system. Once professional addiction counselors are dispatched to schools, they will serve to implement institutional intervention methods to prevent young people's internet addiction in a school-oriented manner.

Fourth, young people living in the contemporary information era can easily access internet game media at home, at school, or in private institutions, owing to relative changes in the digital environment. Thus, the ratio of gaming for young people in daily life is gradually increasing. In particular, the heavy focus of Korea's education culture on college entrance exams restricts offline leisure activities, leading to internet game spaces becoming a reliable leisure and rest option because they allow students to escape from reality without any time and space limitations [23]. Therefore leisure programs, including sporting, cultural, and art activities that can replace gaming and ease stress for young people must be developed and vitalized as part of the school curriculum to build an environment where they can freely enjoy these programs on weekends.

\subsection{Conclusion}

The main objective of this study was to explore the moderating effect of self-efficacy in relation to internet game addiction and aggression. The analysis of the research findings revealed as follows. First, the higher risk group of internet game addiction displayed the higher aggression level compared to other groups. Second, internet game addiction was significantly positively correlated to aggression and aggression was significantly negatively correlated to self-efficacy. Third, self-efficacy simultaneously buffers the effect of internet game addiction upon aggression and decreases the level of aggression.

This study's limitations, as well as suggestions for further studies, are as follows. First, because internet game addiction and aggression levels among young people were measured through self-reporting, this study may not be objective. In addition, no studies on clinical game addiction diagnosis were implemented. Therefore, in-depth follow-up studies are required to verify the regulation effect of self-efficacy on internet game addiction and aggression in young people who have been diagnosed with game addiction. Second, self-efficacy in real life was selected as the study variable, but the relationship between internet game addiction and self-efficacy in virtual spaces was not studied. Doing this is recommended to elucidate the relationship between real life and virtual self-efficacy in relation to internet game addiction and aggression in order to discover which factor has a high moderating effect on aggression. Third, variables related to parents and home life were not assessed. Therefore, in relation to young people's game addiction and aggression, future studies of parent-child interaction and the regulation effect of family leisure activities are suggested. Fourth, it is also important to explore the contents of internet games, such as whether young people play primarily violent games, in order to find out causal relationship between internet games addiction and aggression.

\section{Conflict of Interest}

Author have declared that they have no conflict of interest.

\section{Funding}

This work was supported by the Ministry of Education of the Republic of Korea and the National Research Foundation of Korea (NRF-2020S1A5B8100993).

\section{References}

[1] Lee, H. (2002). Social and psychological variables predicting violence game addiction of adolescents in the Internet, Korean Journal of Psychology, 14 (4), 55-79.

[2] Jeong, S. (2014). The effects of aggression on violent delinquency via game addiction, Journal of Korean Public Police and Security Studies, 10 (4), 171-197.

[3] Korea Creative Content Agency. (2018). The Report of 2018 Game Indulgency. Seoul, Korea.

[4] Kim, O. (2011). Exploring the relationships between game addiction and aggression, Journal of Korea Entertainment Industry Association, 5 (4), 54-62.

[5] Davis, R. A. (2001). A cognitive-behavioral model of pathological Internet use. Computers in Human Behavior, 17 (2), 187-195.

[6] Bandura, A. (1986). Social Foundations of Thought and Action: A Social Cognitive Theory. Englewood Cliffs, NJ: Prentice-Hall.

[7] Strecher, V., Devellis, B., Becker, M., \& Rosenstock, I. (1986). The role of self-efficacy in achieving health behavior change. Health Education Quarterly, 13, 74-92.

[8] Kim, Y. (2013). The moderating effects of self-efficacy and ego-resilience on stress, internet addiction and gambling behavior amongst adolescents, Studies on Korean Youth, 24 (1), 127-156.

[9] Roh, S., \& Kim, J. (2017). The influence of social factors of crisis youth on addiction: Focused on moderating effects of self-efficacy. Korean Association of Addiction Crime Review, 7 (4), 23-41.

[10] Goldberg, J. (1996). Re: Internet addiction disorder. [Electronic mailing list message. Retrieved from http://www.rider.edu/users/suler/psycuber/supportg-p.html.

[11] Young, K. S. (1999). Internet addiction: Symptoms, evaluation and treatment. In L. Vander Creek \& T. Jackson (Eds.), Innovations in Clinical Practice: A Source Book, 19-31.

[12] Eo, G. (2000). Computer Game Addiction Issues and Solutions. The $19^{\text {th }}$ Conference of Special Counseling. Seoul, Korea. 
[13] Kim, J., \& Yu, G. (2008). A Study on the relationship between game addiction and the attacking character of adolescents, Forum for Youth Culture, 17, 34-59.

[14] Kim, B. (2015). Mediation effects of self-regulation and hopelessness between self-efficacy and internet game addiction in middle school students, Korean Public Health Nurse, 29 (3), 441-451.

[15] Han, S., \& Wang, S. (2009). Verification of the moderating effects of the variables related to adolescents' addiction to Internet game and aggression, The Journal of Educational Research, 7 (3), 51-72.

[16] Bandura, A. (1997). Self-Efficacy. New York, W. H. Freeman.

[17] Anderson, C., \& Bushman, B. J. (2002). The effects of media violence on society. Science, 295, 237-2379.

[18] Kim, J. (2009). The relationship among empathy, peer influence, social support and aggression of high school students, Pedagogy Research, 47 (1), 49-72.

[19] Seo, M. (2009). Early adolescents' changes in overt aggression and delinquency, depression/anxiety and perceived academic achievement, Studies on Korean Youth, 53, 141-167.

[20] Kim, E., (2005). Violent computer games, aggressive delinquency, internet delinquency, and internet game addiction in adolescents, Korean Journal of Clinical Psychology, 24 (2), 359-377.

[21] Oh, Y. (2008). The Impact of Internet game addiction on the melancholy, offensiveness and self-esteem of adolescents, Journal of Youth Facility and Environment, 6 (4), 3-15.

[22] Lim, K., Choi, Y., Lee, H., \& Han, J. (2010), The effects of self-efficacy on online game flow - focus on moderating influence of self-control, Journal of the Korean Society for Computer Game, 21, 131-141.

[23] Kwon, J., \& Jeong, H. (2011). Research on the realities and problem behavior pattern of Internet game addiction: Centering on male middle school students from City "J," Korean Association of Addiction Crime Review, 1 (2), 50-68.

[24] Lee, G. (2009). The Prevention Study on Leisure Program for the Family with Game Addiction of Youth, National Youth Policy Institute. Seoul, Korea.

[25] Shim, M., \& Lee, O. (2018). The multiple-mediating effects of self-efficacy and mental health on the influencing relationship between game addiction of adolescents and school adjustment, Humanities and Social Science, 219 (6), 175-190.
[26] Jung, O. (2017). The Understanding of Youth Development. Hakgi Publication, Seoul, Korea.

[27] Roh, K. (2019). The Proper Methods of Statistical Analysis for Dissertation, Hanbit Academy, Inc., Seoul, Korea.

[28] Lim, J. (2016). The mediation model verification of private self-consciousness on game addiction and aggression, Journal of Korean Contents, 16 (4), 250-261.

[29] Ryu, E., \& Ha, E. (2009). Online and offline friendships among adolescents with different types of Internet addiction, Studies on Korean Youth, 20 (2), 5-29.

[30] Holtz, P., \& Appel, M. (2011). Internet use and video gaming predict problem behavior in early adolescence. Journal of Adolescence, 34, 49-58.

[31] Lemmens, J., Valkenburg, P., \& Peter, J. (2011). The effects of pathological gaming on aggression behavior. Journal of Youth and Adolescence, 40, 38-47.

[32] Griffiths, M. (1999). Violent video games and aggression: A review of the literature. Aggression and Violent Behavior 4 (2), 203-212.

[33] Kim, K., Choi, H., Kwon, S., \& Yong, J. (2009). Development and Validation of the Korean Game Addiction Scale for Children and Adolescents, Korean Journal of Clinical Psychology, 14 (3), 511-529.

[34] Kim, S., \& Jeon, J. (2015). The effects of self-efficacy on adolescents' school adjustment: The Mediating Effects of Depression and Aggression, Korean Journal of Child Studies, 36 (4), 193-208.

[35] Cho, H. (2001). The Study on the Juvenile Internet Game Addiction and Personality Traits, Unpublished Dissertation. Han Yang University, Seoul, Korea.

[36] Tipton, R. M., \& Worthington, E. L. (1984). The measurement of generalized self-efficacy: A study of construct validity. Journal of Personality Assessment, 48, 545-548.

[37] Yang, S. (2000). The Development and Effectiveness of Group Program on Empowerment for the Parents with Mentally Retarded Adults. Unpublished Doctoral Dissertation. Seoul National University, Seoul, Korea.

[38] Park, C., \& Kim, D. (2017). The effect of friendship jealousy on relational aggression of early adolescents: Focused on the moderating effect of locus of control and self-efficacy, Korean Journal of Clinical Psychology, 14 (1), 23-39. 